\title{
Reação em campo à murcha bacteriana de cultivares de tomate em Ro- raima
}

\author{
Hyanameyka E de Lima'; ${ }^{1}$ Elizanilda R do Rêgo²; Gilcianny P Cavalcante'; ${ }^{1}$ Mailson M do Rêgo ${ }^{2}$; Luciano \\ V Cota ${ }^{1}$ \\ 'UFV-Depto. Fitopatologia, 36571-000 Viçosa-MG; 2UFPB-CCA, 58397-000 Areia-PB; elizanilda@cca.ufpb.br
}

\section{RESUMO}

A murcha bacteriana causada por Ralstonia solanacearum (Smith) é a doença bacteriana mais importante do tomateiro na Região Norte do Brasil. Os objetivos deste trabalho foram avaliar o nível de resistência de cultivares de tomate, avaliar o progresso da murcha bacteriana nesses genótipos a fim de conhecer o comportamento da doença nos diferentes estádios de desenvolvimento da cultura, para auxiliar no manejo da epidemia, e determinar a época crítica para o desenvolvimento da doença nessas cultivares nas condições de Roraima. Os experimentos foram conduzidos em um campo naturalmente infestado com a biovar 1 de Rasltonia solanacearum, por dois anos. A área tinha um histórico de quatro anos de plantios sucessivos com plantas de tomate suscetíveis à murcha bacteriana, e as perdas alcançando até $100 \%$. Para condução do experimento foram utilizadas mudas das cultivares Majestade, Nemonetta, Carmen, Liliane, Santa Clara, Sensação, San Vito, Gaúcho Melhorado, Hector e Laura. Foram feitas seis avaliações do número de tomateiros que apresentavam murcha irreversível e/ou morte durante o ciclo da cultura. Foram determinadas as variáveis área abaixo da curva de progresso da doença (AACPD) e a taxa de progresso da doença (r), incidência média (Y50), incidência máxima (Ymáx) e a incidência final da doença. Os valores de AACPD e da variável r para a cultivar Majestade foram menores que para as demais, demonstrando que houve menor incidência de plantas doentes nesta cultivar, indicando resistência. Embora o nível de resistência apresentado por esta cultivar não seja muito elevado, o cultivo da mesma é recomendável e viável para o plantio no Estado de Roraima, especialmente considerandose os altos preços do tomate, que são adquiridos de outras regiões produtoras no país, embora somente esta resistência não garanta, sozinha, o controle adequado da doença, sendo necessárias outras medidas de controle associadas.

Palavras-chave: Solanum lycopersicum, Ralstonia solanacearum, área abaixo da curva de progresso da doença, taxa de progresso da doença.

\author{
ABSTRACT \\ Brazil \\ Bacterial wilt resistance in tomato cultivars in Roraima,
}

The bacterial wilt caused by Ralstonia solanacearum is the most important bacterial disease of tomato in the Brazilian North Region. The objectives of this study were to evaluate (1) the resistance level of ten tomato cultivars; (2) the progress of bacterial wilt in these genotypes in order to know the disease behavior in different stages of development of the crop, and (3) determine the critical time to disease development in these cultivars, in Roraima. The experiment was carried out in a field naturally infested with biovar 1 of $R$. solanacearum, during two years. The area was infested by cultivating susceptible tomato plants to bacterial wilt. The cvs. Majestade, Nemonetta, Carmen, Liliane, Santa Clara, Sensação, San Vito, Gaúcho Melhorado, Hector and Laura were cultivated in the infested field. Six disease incidence evaluations were done in seven plants with irreversible wilt and/or death during the crop cycle. The following variables were determined: area under the disease progress curve (AUPDC) and the progress rate (r), mean incidence (Y50), maximum incidence (Ymax) and the final incidence of the disease. The values of AUDPC and the variable $r$ to 'Majestade' were the lowest, although the level of resistance shown by this cultivar was not very high. Therefore, 'Majestade' is recommended for planting in the State of Roraima, especially considering the high prices of tomatoes, which are purchased from other regions in the country. However, only the level of resistance of 'Majestade' is not sufficient for disease control, being necessary other control measures.

Keywords: Solanum lycopersicum, Ralstonia solanacearum, area under the disease progress curve, rate of development of disease.

\section{(Recebido para publicação em 1 de dezembro de 2008; aceito em 2 de fevereiro de 2010) (Received on December 2008; accepted on February 2, 2010)}

$\mathrm{O}$ tomate (Solanum lycopersicum L.) é a segunda hortaliça em importância econômica no Brasil, sendo superada apenas pela batata. $\mathrm{O}$ tomateiro, porém, está sujeito ao ataque de várias doenças que podem limitar sua produção, sendo a murcha bacteriana, causada por Ralstonia solanacearum a doença bacteriana mais importante na Região Norte do Brasil, devido às condições ambientais serem altamente favoráveis ao seu desenvolvimento. Nesta região, a doença se constitui num sério problema ao cultivo de solanáceas e a produção local fica praticamente restrita a pequenas hortas caseiras (Coelho Netto et al., 2004).

Após a introdução da bactéria na área de plantio, o micro-organismo se dissemina com facilidade de diferentes maneiras: pela água que escorre no campo devido às chuvas ou irrigação e pelo solo aderido às máquinas e implementos agrícolas, bem como pelos calçados usados pelos trabalhadores rurais e pessoas que transitam pela área de cultivo (Lopes, 2007).

A temperatura elevada associada com alta umidade do solo e plantas suscetíveis são condições que favorecem ao ataque severo de $R$. solanacearum limitando o cultivo dessas solanáceas, causando a murcha e morte precoce 
das plantas no campo (Cheng \& Chu, 1999; Lopes \& Ávila, 2005). Desta forma, a bactéria é responsável por perdas elevadas na produção de tomate e pela condenação dos campos, especialmente em plantios sucessivos pois a contaminação do solo é tão elevada que torna-se imprópria para o cultivo (Lopes, 2007). Isto tem inviabilizado o cultivo de tomate pelos produtores no estado de Roraima, fazendo com que os supermercados da região sejam obrigados a importar tomate de outras regiões, principalmente da Região Sudeste, consequentemente torna-se cada vez mais caro. Estudos revelam que existe resistência genética consistente já identificada em diferentes espécies de Solanum spp. para a raça 1 que inclui as biovares 1, 3 e 4, permitindo o desenvolvimento de genótipos resistentes à murcha bacteriana do tomateiro (Prior et al., 1994; Hanson et al., 1996). Lopes et al. (1994) e Jaunet \& Luang (1998) mencionaram a dificuldade de se obter genótipos com resistência estável devido à prevalência de estirpes com reação patógeno/hospedeiro variável e Prior et al. (1990) atribuem esta dificuldade também à dependência da resistência se manter em condições ambientais desfavoráveis à hospedeira. Apesar dos esforços da pesquisa, não existem cultivares resistentes, havendo apenas híbridos utilizados como porta-enxertos (Lopes \& Ávila, 2005). O presente trabalho teve por objetivos: a) avaliar o nível de resistência de 10 cultivares de tomate, em solo naturalmente infestado com a raça 1 , biovar 1 da bactéria $R$. solanacearum; b) avaliar o progresso da murcha bacteriana nesses genótipos a fim de se conhecer o comportamento da doença nos diferentes estádios de desenvolvimento da cultura, para auxiliar no manejo da epidemia, e c) determinar a época crítica para o desenvolvimento da doença nessas cultivares comerciais nas condições de Roraima.

\section{MATERIAL E MÉTODOS}

Os experimentos foram instalados e conduzidos em uma propriedade, localizada no município de Boa Vista, RR, de outubro de 2005 a março 2006 e de outubro 2006 a março de 2007 . No segundo experimento, entretanto, só foi feita a avaliação da incidência final, para confirmar os resultados do primeiro experimento.

A área utilizada para execução deste experimento possuía um histórico de quatro anos de plantio sucessivos com cultivares de tomates suscetíveis à murcha bacteriana, que registraram perdas de até $100 \%$, aumentando com isso a pressão de inóculo no local. Com base nesse histórico, considerou-se que a quantidade natural de inóculo onde foi realizado o experimento foi suficiente e adequada para garantir a ocorrência da doença em proporção passível de análise e identificação clara de indivíduos resistentes e suscetíveis, minimizando ao máximo a possibilidade de escape das plantas suscetíveis.

O delineamento experimental foi em blocos casualizados, com 10 tratamentos (10 cultivares) e três repetições, sendo a parcela constituída de 100 plantas. Para isto, foram utilizadas as dez cultivares de tomate mais comercializadas em Roraima: Majestade, Nemonetta, Carmen, Liliane, Santa Clara, Sensação, San Vito, Gaúcho melhorado, Hector e Laura. As mudas foram produzidas em bandejas de isopor de 128 células, sob ambiente protegido, onde permaneceram por 21 dias após a semeadura realizada em outubro de 2005 e 2006. O transplante foi realizado quando as mudas possuíam cerca de quatro folhas definitivas. Durante o desenvolvimento das plantas foi determinada a incidência de murcha bacteriana em cada tratamento, por meio da contagem do número de plantas de tomateiros que apresentavam murcha irreversível e/ou morte, totalizando seis avaliações durante o ciclo da cultura $(15,35,55,75,85$ e 100 dias após o transplante). A incidência foi registrada a partir da primeira ocorrência de planta com sintomas de murcha, de modo a acompanhar o progresso da doença ao longo do tempo. As plantas que apresentaram sintomas de murcha irreversível foram submetidas a testes de exsudação para a confirmação da etiologia bacteriana. De cada repetição foram selecionadas de 12 a 27 plantas sintomáticas, dependendo da cultivar, e estas foram enviadas ao laboratório de Biologia Molecular da UFRR para isolamento do patógeno. Retirou-se cerca de $8 \mathrm{~cm}$ do caule de cada planta, os quais foram exaustivamente lavados com água e detergente, enxaguados e secos com papel toalha e, em seguida, flambados em álcool absoluto por duas ou três vezes (Romeiro, 2001). Dentro da câmara de fluxo, foi realizado o procedimento de isolamento, por meio da exsudação em tubos de ensaio contendo água destilada esterilizada. Os fragmentos do caule foram mantidos nessa condição por cerca de 10 minutos, garantindo a descida do fluxo bacteriano até que a água se tornasse bastante turva. Após este período, o órgão vegetal foi retirado de dentro do tubo de ensaio, e com auxílio de uma alça plástica calibrada de $10 \mu \mathrm{L}$, retirou-se a suspensão bacteriana para o semeio pelo método de estrias ou riscas em meio Kelman ou de cloreto de trifenil tetrazólio-TZC (Kelman, 1954), a fim de confirmar a infecção dos tomateiros por $R$. solanacearum. As placas foram mantidas a $\pm 28^{\circ} \mathrm{C}$, posteriormente as colônias virulentas (brancas com o centro róseo) foram repicadas para a preservação em água destilada esterilizada a $22^{\circ} \mathrm{C}$ (Klement et al., 1990). Foi realizada a caracterização bioquímica dos isolados de $R$. solanacearum encontrados na área experimental seguindo a metodologia descrita por Schaad et al. (2001), para determinar qual ou quais biovares de $R$. solanacearum encontravam-se na área de plantio. Todos os isolados obtidos foram submetidos ao teste de patogenicidade em plantas da cv. Santa Clara, por meio do método de injúria nas raízes e imersão em suspensão bacteriana (Romeiro, 2001). Para as plantas utilizadas como testemunha a suspensão de bactérias foi substituída por água destilada deionizada e autoclavada.

Os dados de incidência foram utilizados para calcular a taxa de progresso da doença (r) e a Área Abaixo da Curva de Progresso da Doença (AACPD) para cada cultivar. Com os valores médios, foram estimados os valores de incidência da murcha bacteriana na metade da epidemia, incidência média $\left(\mathrm{Y}_{50}\right)$, e a incidência final da epidemia, incidência máxima $\left(\mathrm{Y}_{\text {máx }}\right)$. Os dados de $\mathrm{Y}_{50}, \mathrm{Y}_{\text {máx }}$ e AACPD foram submetidos à análise de variância e foram comparadas as 
médias pelo teste Fisher LSD a 5\% de probabilidade. As estimativas das taxas de progresso da doença (r) entre os tratamentos foram comparadas por meio do intervalo de confiança a $95 \%$ de probabilidade (Campbell \& Madden, 1990). Todas as análises foram realizadas com o programa SAS System versão 8.0.

\section{RESULTADOS E DISCUSSÃO}

A partir de 15 dias após o transplante, todas as cultivares já evidenciavam o início dos sintomas típicos da doença caracterizados pela murcha das folhas apicais, especialmente nas horas mais quentes do dia. Houve diferença no avanço da doença entre os tratamentos, como pode ser visto na curva de progresso da doença, que refletiu a intensidade da doença através do tempo em que ocorreu a epidemia (Tabela 1). O modelo que melhor ajustou aos dados de progresso foi o logístico. Na variável $\mathrm{Y}_{50}$ foram observados dois agrupamentos no progresso da doença (Tabela 1), demonstrando que as cultivares Liliane,
Carmen, Nemonetta e Majestade tiveram o início da epidemia retardado, porém ao longo do tempo se igualaram com as demais cultivares que apresentaram $\mathrm{Y}_{50}$ maior, exceto 'Majestade'.

Houve aumento na quantidade de doença em função do tempo em todos os tratamentos, porém a AACPD da cultivar Majestade foi menor que as demais, podendo ser atribuído a uma maior resistência da mesma ao patógeno, retardando o início da epidemia, reduzindo a intensidade final da doença e a duração da epidemia. A cultivar Laura foi a mais suscetível à doença, pois a AACPD foi maior que as demais (Tabela 1, Figura 1). O progresso da doença na cultivar Majestade foi mais lento, indicando uma possível resistência, já que as cultivares foram mantidas sob as mesmas condições com relação a tratos culturais, como adubação, irrigação, entre outros. Para a variável $\mathrm{Y}_{\text {máx }}$ houve diferença entre os tratamentos, a cultivar mais suscetível 'Laura' obteve um valor de 96 para o $\mathrm{Y}_{\text {máx }}$ enquanto a mais resistente, 'Majestade', obteve $\mathrm{Y}_{\text {máx }}$ de 44. O mesmo comportamento foi

Tabela 1. Incidência da murcha bacteriana aos $50\left(\mathrm{Y}_{50}\right)$ e 100 dias $\left(\mathrm{Y}_{\text {máx }}\right)$ após o transplante, área abaixo da curva de progresso da doença (AACPD) e taxa de progresso da doença (r), estimada com o modelo logístico, em diferentes cultivares de tomate (Solanum lycopersicum) (incidence of bacterial wilt to the $50\left(\mathrm{Y}_{50}\right)$ and 100 days $\left(\mathrm{Y}_{\text {máx }}\right)$ after the transplant, Area Under the Disease Progress Curve (AUDPC) and the rate of development of disease (r), estimated with the logistic model, in different tomato (Solanum lycopersicum) cultivars). Viçosa, UFV, 2007.

\begin{tabular}{lcclll}
\hline Tratamento & $\mathbf{Y}_{\mathbf{5 0}}$ & $\mathbf{Y}_{\text {máx }}$ & $* \mathbf{Y}_{\text {máx }}$ & AACPD & $\mathbf{R}$ \\
\hline Gaúcho Melhorado & $58 \mathrm{a}$ & $91 \mathrm{a}$ & $87 \mathrm{abc}$ & $4507,5 \mathrm{a}$ & $0,0623 \mathrm{a}$ \\
Laura & $52 \mathrm{ab}$ & $96 \mathrm{a}$ & $97 \mathrm{a}$ & $4817,5 \mathrm{a}$ & $0,0715 \mathrm{a}$ \\
Hector & $51 \mathrm{bc}$ & $96 \mathrm{a}$ & $93 \mathrm{ab}$ & $4467,5 \mathrm{ab}$ & $0,0687 \mathrm{a}$ \\
Sensação & $47 \mathrm{~cd}$ & $89 \mathrm{a}$ & $87 \mathrm{abc}$ & $4027,5 \mathrm{bc}$ & $0,0615 \mathrm{a}$ \\
San Vito & $45 \mathrm{~cd}$ & $89 \mathrm{a}$ & $89 \mathrm{abc}$ & $4065,0 \mathrm{bc}$ & $0,0605 \mathrm{a}$ \\
Santa Clara & $43 \mathrm{~d}$ & $80 \mathrm{~b}$ & $81 \mathrm{bc}$ & $3905,0 \mathrm{c}$ & $0,0504 \mathrm{bc}$ \\
Liliane & $19 \mathrm{e}$ & $73 \mathrm{bc}$ & $75 \mathrm{~cd}$ & $2952,5 \mathrm{~d}$ & $0,0618 \mathrm{a}$ \\
Nemonetta & $16 \mathrm{ef}$ & $58 \mathrm{~d}$ & $60 \mathrm{~d}$ & $2270,0 \mathrm{e}$ & $0,0484 \mathrm{c}$ \\
Carmen & $12 \mathrm{f}$ & $69 \mathrm{c}$ & $64 \mathrm{~d}$ & $2545,0 \mathrm{de}$ & $0,0630 \mathrm{a}$ \\
Majestade & $11 \mathrm{f}$ & $44 \mathrm{e}$ & $39 \mathrm{e}$ & $1725,0 \mathrm{f}$ & $0,0396 \mathrm{~d}$ \\
\hline CV (\%) & & 5,92 & 11,57 & 6,92 & 7,60 \\
\hline
\end{tabular}

*Ymáx de 2007; Médias seguidas da mesma letra, na mesma coluna, não diferem entre si, pelo teste de Fisher LSD $(\alpha=0,05)$. Valores de $r$ seguidos da mesma letra não diferem entre si, em intervalo de confiança de $95 \%$ de probabilidade, da diferença entre as estimativas do parâmetro (means followed by the same letter, in the same column, do not differ to each other, for Fisher LSD'S test $(\alpha=0,05)$. Values of $r$ followed by the same letter do not differ from each other, according to the trust interval, to $95 \%$ of probability, of the differences among the estimates of the parameter).

observado no segundo ano de avaliação para as cultivares Majestade e Laura (Tabela 1). Existe uma variabilidade na agressividade de isolados dos biovares 1 e 3 , sendo que uma maior agressividade em tomateiros nos isolados pertencentes ao biovar 1 foi constatada por Lopes et al. (1994). Coelho Neto et al. (2003), em trabalho com isolados do Estado do Amazonas, demonstraram a existência de variabilidade na agressividade dos 41 isolados testados. Com os dados obtidos neste trabalho não foi possível determinar correlação entre biovar e agressividade ou sobre resistência diferencial conforme observado por Lopes et al. (1994), entretanto a determinação dos biovares e das cultivares menos suscetíveis aos mesmos é de fundamental importância para o melhoramento da cultura do tomateiro visando resistência à murcha bacteriana.

Os isolados da bactéria obtidos a partir de plantas que apresentaram murcha irreversível (suscetíveis), bem como, daquelas que apresentaram algumas folhas e pecíolos murchos, quando submetidos ao teste de patogenicidade, comportaram-se como virulentos, pois todas as plantas inoculadas murcharam e morreram, enquanto as plantas tratadas com água (plantas controle) permaneceram vivas e vigorosas. Foram realizados testes bioquímicos que permitiram a caracterização dos isolados coletados, como sendo a biovar 1 de $R$. solanacearum. Na região Norte a biovar 1 é predominante na cultura do tomate, embora seja encontrado também a biovar 3, porém mais associado às culturas do pimentão e pimenta (Coelho Neto et al. 2004; Coelho Neto et al. 2003). Esses dados são também corroborados pelo trabalho de Lopes et al. (1998) que associaram a presença de isolados da biovar 1 a locais de clima mais quente.

Desta forma, as plantas que apresentaram produção de frutos de tomate, mesmo infectadas pela bactéria, apresentaram algum nível de resistência, e isto variou conforme a cultivar. Assim, 'Majestade', que apresentou maior resistência pode ser considerada viável para o cultivo no estado de Roraima, embora somente esta resistência não garanta, sozinha, o controle adequado da doença, sendo necessárias outras medidas de controle associadas. $\mathrm{O}$ aumento da área 


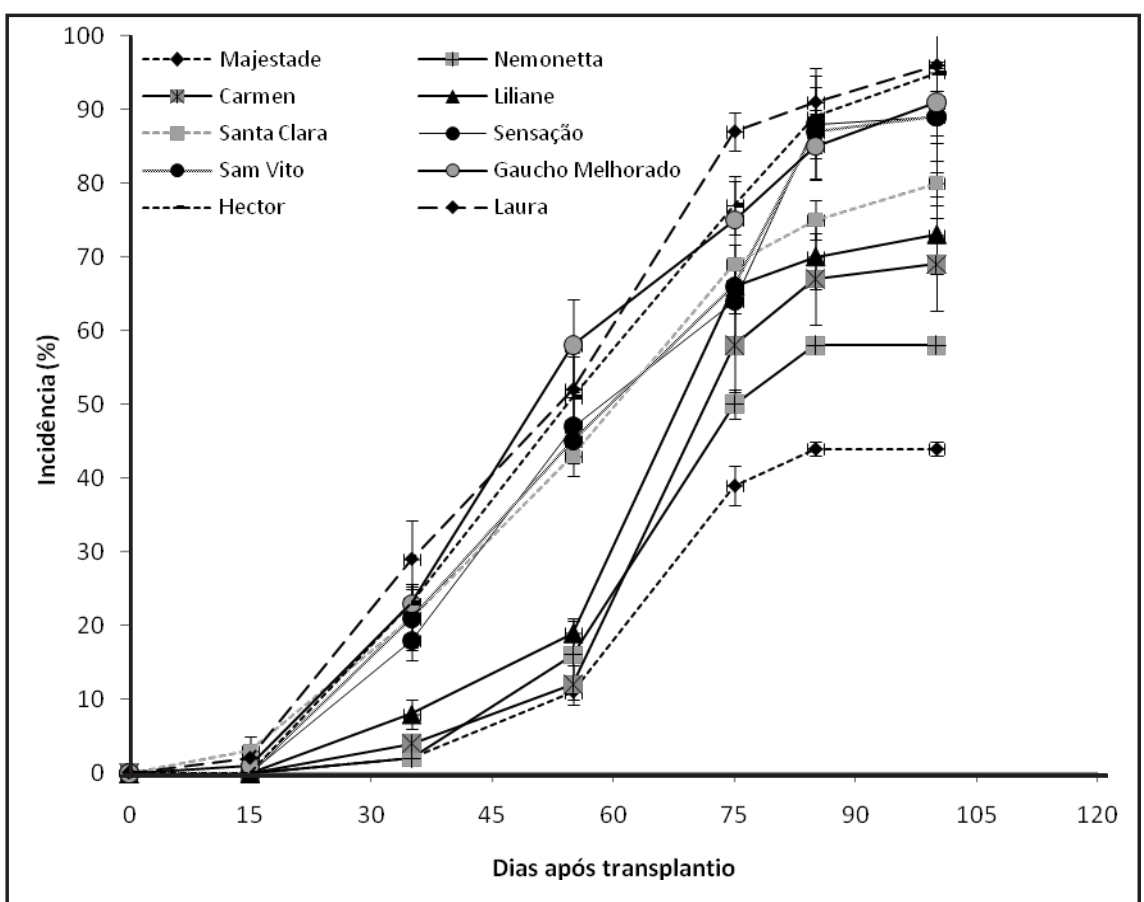

Figura 1. Progresso da murcha bacteriana em cultivares de tomate. Avaliação em campo naturalmente infestado com a biovar 1 de Ralstonia solanacearum (progress of the bacterial wilt in tomato varieties. Evaluation in field naturally infested with biovar 1 of Ralstonia solanacearum). Boa Vista-RR, 2006.

plantada com tomate poderá contribuir para a redução do preço do produto, tornando esta hortaliça mais acessível à população local.

\section{AGRADECIMENTOS}

Os autores agradecem ao Eng. Agr. Aurio Tessaro, pelo apoio técnico e uso das instalações para execução do ensaio e também ao Prof. Eduardo Mizubuti (Depto. Fitopatologia, UFV), pelas sugestões.

\section{REFERÊNCIAS}

CAMPBELL CL; MADDEN LV. 1990. Temporal analysis of epidemics I: Description and comparison of disease progress curves. In: CAMPBELL CL; MADDEN LV (eds). Introduction to plant disease epidemiology. New York, p. 161-202.

CARMEILLE A; PRIOR P; KODJA H; CHIROLEU F; LUISETTI J; BESSE P. 2006. Evaluation of resistance to Race 3, Biovar 2 of Ralstonia solanacearum in Tomato Germplasm. Journal of Phytopathology 154: 398-402.
CHENG SS; CHU EY. 1999. Tomaticultura em gramado, na região do Trópico Úmido Brasileiro. Circular Técnica, 3, Embrapa Amazônia Oriental, Belém, 28 p.

CINTRA WJJ; POZZA EA; VALE FXR; AGUILERA GM. 2004. Análise Temporal de Epidemias. In: VALE FXR; CINTRA WJJ; ZAMBOLIM L. Epidemiologia Aplicada ao Manejo de Doenças de Plantas. Belo Horizonte: Perfil editora. p. 131-161.

COELHO NETTO RA; PEREIRA BG; NODA H; BOHER B. 2004. Murcha bacteriana no estado do Amazonas, Brasil. Fitopatologia Brasileira 29:1723.

COELHO NETTO RA; PEREIRA BG; NODA H; BOHER B. 2003. Caracterização de isolados de Ralstonia solanacearum obtidos de tomateiros em várzea e em terra firme no Estado do Amazonas. Fitopatologia Brasileira 28:362-366.

HANSON PM; WANG JF; LICARDO O. 1996. Variable reaction of tomato lines to bacterial wilt evaluated at several locations in southeast Asia. Hortscience 31:143-146.

HAYWARD AC. 1991. Biology and epidemiology of bacterial wilt caused by Pseudomonas solanacearum. Annual Review of Phytopathology 29:65-87.

HAYWARD AC. 1994. The hosts of Pseudomonas solanacearum. In: HAYWARD AC; HARTMAN GL (eds). Bacterial Wilt: The Disease and Its Causative Agent, Pseudomonas solanacearum, Wallingford, UK, CAB International, pp. 9-25.

JOUNET TX; WANG JF. 1999. Variation of genotype and aggressiveness of Ralstonia solanacearum race 1 isolated from tomato in Taiwan. Phytopathology 89:320-327.

KELMAN A. 1954. The relationship of pathogenicity of Pseudomonas solanacearum to colony appearance on a tetrazolium medium. Phytopathology 44: 693- 695 .

KLEMENT Z; RUDOLPH K; SANDS DC. 1990. Methods in phytobacteriology. Budapest: Akademiai Kiadó, 568 p.

LAFORTUNE D; BÉRAMIS M. 2005. Partial Resistance of Pepper to Bacterial Wilt Is Oligogenic and Stable Under Tropical Conditions. Plant Disease 89:501-506.

LIMA NETO AF. 2005. Avaliação da Resistência de clones e cultivares de batata à murcha bacteriana (Ralstonia solanacearum). Brasília: Universidade Federal de Brasília. 108p.(Tese doutorado).

LOPES CA; ÁVILA AC. Doenças do tomateiro. Embrapa Hortaliças, Brasília, DF. 2005.152p.

LOPES CA; DUVAL AMQ. 2007. Epidemiologia e controle das bacterioses das hortaliças. In: ZAMBOLIM L; LOPES CA; PICANÇO MC; COSTA H.(Eds.). Manejo Integrado de Doenças e Pragas: Hortaliças. Viçosa: Editora UFV, 502p.

LOPES CA; QUEZADO-SOARES AM; MELO PE. 1994. Differential resistance of tomato cultigens I and II of Pseudomonas solanacearum. Plant Disease 78: 1091-1094.

LOPES CA; QUEZADO-SOARES AM; BUSO JA; MELO PE. 1998. Breeding for resistance wilt of potatoes in Brazil. In: Reports of the $2^{\text {nd }}$ International Bacterial Wilt Symposium. Guadeloupe. p.290-293. 
PRIOR P, GRIMAULT V, SCHMIT J. 1994.

Resistance to bacterial wilt (Pseudomonas solanacearum) in tomato: present status and prospects. In: HAYWARD AC, HARTMAN GL (eds). Bacterial Wilt: The Disease and Its Causative Agent, Pseudomonas solanacearum, Wallingford, UK, CAB International, p. 209-223.

UFV, 279p.

PRIOR P; STEVA H; CEDET P. 1990. SCHAAD NW; JONES JB; CHUN W. Agressiveness of strains of Pseudomonas solanacearum from the French West Indias (Martiniqye and Guadalupe) on tomato. Plant Disease 74: 962-965.

ROMEIRO RS. 2001. Métodos em bacteriologia de plantas. Viçosa: Editora
2001. Laboratory guide for identification of plant pathogenic bacteria. $3^{\text {rd }}$ ed. American Phytopathological Society Press, St. Paul, 373p. 